\title{
Dermatoglifos y diabetes infantil
}

El motivo de la presente comunicación es contribuir, en lo posible, a esclarecer la relación entre diabetes infantil, sus antecedentes hereditarios y su patrimonio genético.

Con estc propósito se eligen al azar un grupo de 50 pacientes controlados en el Depto. de Nutrición y Diabetes del Hospital San Juan de Dios, a los cuales se les estudió sus impresiones dermopapilares con la intención de averiguar

* Departarkento Cienética.

* Departamento de Nutricion y Diabetes.
Drs.: Jaime Herrera*, Eric Schilling*", lris Mella"* y Manuel Garcia de los Rios**

si éstas obedecian a un patrón determinado que pudiera servir para este objeto.

\section{MATERIAL Y METODO}

Se toman al azar 50 pacientes diabéticos infantiles controlados en el Departamento y que han sido cuidadosamente estudiados en él, y cuyas caracteristicas generales fueron descritas por Iris Mella y col. en 1973'. En estos enfermos su diabetes se inició antes de los 15 años en el $100 \%$ de ellos. 
Se analizan las impresiones dermopapilares digitales de estos pacientes, comparándolos con patrones de la población del Norte, Centro y Sur de nuestro país, más un grupo de araucanos y los porcentajes conocidos de dermatoglifos caucásicos tomados de la literatura especializada internacional. Los dermatoglifos del Norte y Sur del país fueron obtenidos por las Dras. Mateluna, Vivanco y Avendaño, y publicarlos en la Revista de Antropologia de Santiago", entre los años 1967 y 1968 . En estos artículos se hace mención a los trabajos de Henckel, en 1933, sobre araucanos. Los controles de Centro corresponden a nuestro material del Laboratorio de Genética.

\section{RESULTADOS}

En la tabla 1 se demuestra igual frecuencia para ambos sexos y un porcentaje de $52 \%$ para los hombres y $40 \%$ para las mujeres de antecedentes hereditarios semejante al obtenido por la Dra. Mella. Estos antecedentes son porcentualmente del todo semejantes para ambas líneas paternas y matemas, respectivamente.

Del análisis de estos glifos se desprenden ciertas diferencias entre los pacientes y los controles de la población chilena, como asimismo, ciertas semejanzas entre éstos y las estructuras de tipo caucásicos.

Efectivamente, tanto los grupos controles capitalinos, nortinos y araucanos muestran un porcentaje de remolinos sobre el $33 \%$ que está a 6 puntos del promedio de nuestros enfermos y a 5 del promedio caucásico. Lo mismo ocurre, pero en sentido inverso, con los porcentajes de asas cubitales que en las razas de tipo caucásicas son bastante más altos que en nuestros controles e incluso que en nuestros pacientes, pero éstos tienen de todas maneras un porcentaje superior a los controles. Esto se hace más evidente si se suman las asas cubitales y radiales. Es interesantc anotar que estas diferencias no se aprecian en los controles sureños, que tienen también una gran semejanza con los poncentajes caucásicos y diabéticos. Interesante resulta recalcar también el alto porcentaje de arcos que tienen nuestros enfermos, cosa que es semejante en todos los controles, menos en el norte y araucanos que tienen un porcentaje similar a los caucásicos. Este hecho hace que, en goneral, el indice de Cummins no presente valores signi-
Tabla 1

\begin{tabular}{|c|c|}
\hline Distribucion pot sexo & Antecedentes hereditanos \\
\hline \multirow[t]{2}{*}{ \& $25-50 \%$} & \& P $7-28 \% M 6-24 \%$ \\
\hline & Total $52 \%$ \\
\hline \multirow[t]{3}{*}{ ? $25-50 \%$} & q $\mathbf{p 5}-20 \%$ M5-20\% \\
\hline & Total $40 \%$ \\
\hline & Ambos $2-8 \% 3.12 \%$ \\
\hline
\end{tabular}

Tabla 2

DISTRIBUCION DE FIGURAS DIGITALES EN NUESTROS ENFERMOS Y GRUPOS CONTROL \%

\begin{tabular}{lrrrrrrr}
\hline & Diabet & Cawc. & Centro & Niorte & \multicolumn{1}{c}{ Sur } & Araw. \\
\hline A C & 55.6 & 61.5 & 51.3 & 51.3 & 57.1 & 56 \\
A R & 3.2 & 4.5 & 2.8 & 3.5 & 3.2 & \\
R & 27.1 & 28.5 & 33.9 & 35.5 & 29.2 & 37 \\
Arcos & 14.0 & 5.5 & 11.4 & 5.8 & 10.6 & 7 \\
IPI & 11.8 & 11.5 & 11.5 & 13 & 11.8 & 13 \\
\hline
\end{tabular}

Tabla 3

DISTRIBUCION DE ASAS PALMARES

\begin{tabular}{lrrrr}
\hline & \multicolumn{2}{c}{ Dabeticos } & \multicolumn{2}{c}{ Control } \\
\hline 2 & \multicolumn{1}{c}{ Area } & 9 & & \\
\hline 3 & $16 \%$ & $8 \%$ & $4 \%$ & $0 \%$ \\
4 & $29 \%$ & $68 \%$ & $20 \%$ & $23 \%$ \\
Hipot. & $100 \%$ & $84 \%$ & $24 \%$ & $32 \%$ \\
\hline
\end{tabular}

Tabla 4

DISTRIBUCION DE FIGURAS DIGITALES POR SEXO \%

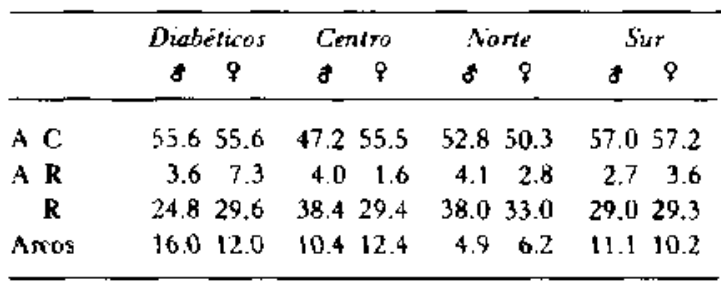

ficativos, ya que el alto porcentaje de remolinos es neutralizado por el aito porcentaje de arcos.

El porqué la gente del Norte hace excepción a esta regla, no tenemos una explicación clara, en cambio nos parece muy lógica la semejanza entre los sureños y caucásicos, dada la gran afluencia de inmigrantes caucásicos que tiene esta zona en nuestro pais. Si separamos los grupos por sexos, esta diferencia se hace más significativa en los hombres. 
Un estudio de las figuras palmares nos muestra un alto porcentaje de asas interdigitales $e$ hipotenares, especialmente en el área 4 entre el $4^{\circ}$ y $5^{\circ}$ dedos. Su diferencia con los controles es significativa.

Este hecho, aunque no es específico, es evidente que tiene el mismo significado que en otros cuadros de origen genético, como las disgenesias, trisomías, etc. No se encontraron otras alteraciones más allá de los límites normales en los surcos, trirradios, ángulo atd, o recuento de crestas digitales.

\section{COMENTARIO}

Del análisis del material presentado, se desprende que la conformación de las figuras dermopapilares de nuestros pacientes son más cercanas a las proporciones de los caucásicos que a la de los controles, con la sola excepción de los sureños.

Si bien es cierto que las diferencias proporcionales de las figuras no son demasiado evidentes, la conformación total de las manos es significativamente diferente. Uno de los signos más claros de este hecho lo constituye el alto número de remolinos que tienen los controles y que constituyen una clara diferencia con el tipo caucásico y que no lo tienen nuestros diabéticos.

La semejanza que existe entre los diabéticos, sureños y caucásicos nos hace pensar, con bastante fundamento, que los genes determinantes de la falla estructural del páncreas, son de origen caucásico. Este hecho tiene aún más validez si se piensa que en las razas indígenas puras (araucanos, mapuches, etc.), prácticamente no se conoce la diabetes infantil.

Por último, el alto porcentaje de figuras palmares $e$ interdigitales confirman una precoz alteración embriológica de estos enfermos.
Es necesario aclarar que esta publicación tiene sôlo el carácter de preliminar, ya que el 1) guirán estudiando este problema en todos sus pacientes y lo harán extensivo a sus parientes.

\section{RESUMEN}

be estudian 50 pacientes con diahetes infantil y su relación con patrones en sus dermatoglifos.

be encuentra en ellos una gran semejarza con los patrones caucásicos y marcadas diferencias con los controles rhilenos, excepto los del Sur.

Se dedure una posibie transmisión de genes alterartos por inmigrantes.

\section{SUMMARY}

50 infantile diabetis pariens and their relations with dermatoglyphics patterns are studied.

A great resamblance with caucasians pattems, and it greath difference with chileans patterns contmls, except southern one, is found.

A possible immigrant altered genes transmitions is detected

\section{REFERENCIAS}

'Mella, Iris; Garcia de bos Rios, Manuet, Rev. Child. Ped, V'ol. 44, mayo 1973.

2 Mateluna, Esier; Azendaño, Isabet. Antropologíat. Vol. $w, N^{\circ}$ único, $1966-67$.

- Mateluna, Ester; Vivanco. Kimena. Dermatoglifos en 4 ciudades de la provincia de Chiloé. En prensa.

- Alker, Miltorn. Amer. J- Dis. Child, Vol. 120, Nov. 1970.

5 David T.J. Arch. Dis. in Chilhood., Vol. 48-191. 1973.

- Ford, Homa. Ped. Clin. of North Amer. 5-531, Mas 58.

J Mitler, James $R$. The J. of Invest. Dermat, Vol. 60 , $N^{*} 6,1973$.

- Penrose. The Lancet. June-1239, 1973.

- Holt, Sarah B. Clinic, Pediat., Vol, 12, N 8, Aug. 1973.

10 Lethida, trene. Ped. Cli. of North Amer., Val. 2. 1963

"Hirsch. Rev. Chil. Ped, enero 1967.

12 Lacassie, rives. Rev. Chil. Ped. Sept. y Oct. 1967. 